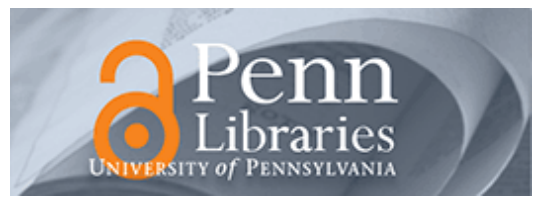

Studies in Visual Communication

Volume 8

Issue 3 Summer 1982

Article 3

1982

\title{
Okpella Masks: In Search of the Parameters of the Beautiful and the Grotesque
}

Jean M. Borgatti

\section{Recommended Citation}

Borgatti, J. M. (1982). Okpella Masks: In Search of the Parameters of the Beautiful and the Grotesque. 8 (3), 28-40. Retrieved from https://repository.upenn.edu/svc/vol8/iss3/3

This paper is posted at ScholarlyCommons. https://repository.upenn.edu/svc/vol8/iss3/3

For more information, please contact repository@pobox.upenn.edu. 
Okpella Masks: In Search of the Parameters of the Beautiful and the Grotesque 


\title{
Okpella Masks: In Search of the Parameters of the Beautiful and the Grotesque
}

\author{
Jean M. Borgatti
}

\section{Introduction}

The Okpella, an Edo-speaking people living north of Benin City in southern Nigeria, number about 35,000 persons in nine villages. They may be described as politically decentralized, although Okpella society is hierarchically organized according to a complex of factors including birthright, achievement, and age. The Okpella currently maintain three main masking traditions. The oldest, a fiber masquerade linked to age sets and titles, is in the process of being supplanted by a group of cloth and wooden masks introduced circa 1900. These masks are performed in conjunction with a festival honoring ancestors. The third tradition, a dance widely performed in social contexts, was introduced after 1920. For this dance performers wear a specific set of costumes made of cloth appliqué.

Analysis of data collected in Okpella between 1972 and 1974 indicates that the people who today identify themselves as Okpella have undergone a series of transformations since the sixteenth century. Within relatively recent times, between 1880 and 1920, it can be documented that those transformations have been marked or accompanied by radical changes in aesthetic choices. ${ }^{1}$ Both social change and shifts in taste may be seen as responses to historical circumstances: a period of great social upheaval followed by one of relative stability, increased interethnic contact during both periods, and the availability of new materials and technology.

The political and economic ferment characterizing Nigeria today creates a climate analogous in many respects to that which existed around the turn of the century, and change continues apace. Okpella, rather a backwater in 1973, now finds itself with an expanded economic base and an advantageous location for transshipping farm produce and other goods between the north and the south of Nigeria. The ancestral festival has flourished in this atmosphere, making it possible in 1979 to assess qualitatively changes in the festival -in masks, regalia, characterizations, patronage, the size and location of performing units, and so on, in relation to phenomena observed in 1973. At the same time a survey was carried out in an attempt to define more specifically the criteria underlying the Okpella aesthetic and the circumstances that affect aesthetic choices. ${ }^{2}$

Jean M. Borgatti is Research Associate, Department of Art History, University of Washington, and Research Associate, Department of African Studies, Boston University. She is at present working on two books: Social Change and Okpella Aesthetic Attitudes, based on a 400-interview survey, and Baskets of Luck and Money: Olimi Festival in Okpella.
This article is a preliminary report on this research focusing on issues of aesthetic preference in one community, Ogiriga. ${ }^{3}$ Ogiriga was one of the points of origin for the Olimi festival, an annual festival honoring ancestors held by four of the nine Okpella villages. Olimi festival not only provides the context in which a variety of masquerades perform, but it also is the vehicle by which these masquerades were - and continue to be -introduced into Okpella. Ogiriga village is also the home of Okpella's best-known mask-makers: Lawrence Ajanaku, Stephen Isah, Samuel Belu, James John, and Shedetu Bekon.

\section{Methodology}

The survey questionnaire 4 (300 questions) was administered to a random sample of Okpella households. In each of 70 compounds (afe), six people were interviewed: the male head of household, the senior female, two other adults, one male, one female chosen through a random process, one child chosen through a random process, and one specialist in the arts-an artist or craftsperson [atsona) or a virtuoso performer [okelo] - chosen by the compound head. (It is interesting that at least four of the six persons in each compound considered themselves to be craftspersons in one of a wide variety of categories or to be performers of note in one or more genres.) Two-thirds of the interviews were drawn from the four towns where the ancestral Olimi masking festival is held and one-third from the remaining five towns.

The survey was intended to elicit verbal statements about art and performance in a culture that chooses not to verbalize its criticism of consecrated objects, a culture in which the aesthetic is "unvoiced" - to use Roy Sieber's term. It is significant to note that people who refused to discuss preferences for specific masks when questioned informally with photographs in 1973 and 1974 had no hesitation in making preference statements when confronted with photographs of these same masks within a formal program of questions. Very few-indeed, fewer than anticipated - opted for responses of "no opinion" or "no reply" regardless of age, sex, or religious preference.

The survey was further intended to determine the bases for aesthetic judgment in Okpella culture, to find out what individuals look at when they admire a mask. Analysis of the survey data should permit the characterization of the ideal for a given category of mask in the mind's eye of each individual, as well as the measurement of deviation from this ideal image (in terms of personal preference). Ultimately, the intent is to determine the differences in aesthetic attitudes held by the articulators of the aesthetic-those most closely associated with the creation of art objects and the production of art events, the artists, elders, and cult leaders - and the consumers of aesthetic products, the general public that makes up the audience, and what other factors - age, sex, educa- 
tion, religion, status, experience of the outside world, and so on-affect aesthetic choices.

The questionnaire included both open- and closedended questions. An attempt to find converging evidence was made in the overlapping of verbal questions based on hypothetical but culturally embedded art and performance situations and those focusing on the visual stimuli. The final version of the questionnaire was in the Okpella language, the language in which the interviews were held. ${ }^{5}$

Questions focusing on visual stimuli were interspersed with purely verbal ones in order to change the pace of the interview and help allay possible boredom and resulting response set.

Five research assistants were employed -one postsecondary school student, two secondary school graduates, one fourth-form student, and one graduate of primary six. The latter was the only woman and was the younger wife of a chief. The bulk of the interviewing was done in the respondents' homes. After preliminary visits in which the purpose of the survey was explained and the individuals to be interviewed selected, a research team consisting of interviewers and the principal investigator would return to the compound on an appointed day and interview simultaneously as many persons (up to five) as were available, returning at some later time to interview the remaining respondent(s). The principal investigator did no interviewing, monitoring instead each research assistant during his or her interview. Interviews averaged $1 \frac{1}{2}$ hours in length.

The questionnaire contained clusters of related questions as well as individual questions on art and performance. The first group of questions (1-10) was addressed to the compound head only and concerned general information about the compound and its inhabitants, e.g., location, the number of masquerades owned by compound members (if any), the number of persons considered craftspersons or virtuoso performers, and so on. The second cluster (11-80) focused on the individual respondent's background and lifestyle: place of birth, lineage affiliation, sex, age, age group, occupation, education, religion, marital status, places of residence, travel experience, exposure to the culture of other Nigerian ethnic groups, exposure to the outside world via radio, TV, or cinema, traditional status, involvement in craftwork or performance. There were questions on patronage situations $(81-88,112)$, specifically on the commissioning and acceptance of masks, to test the acceptability of certain deviations from existing norms or canons. Another series of questions (89-111, 113-120) was based on the appearance of masquerades typically representing a deceased female (Olimi Nikeke), the festival herald (Anogiri), and a deceased male (Omeshe). Contrasting descriptors in the answers were in part based on qualitatively elicited information from previous research and were chosen to test inferred information. Certain contrasting descriptors were selected to test the comparability of Okpella's aesthetic criteria with those established by Thompson (1973) for the Yoruba.

Other important questions focused on the characteristics of the artist as a concept (e.g., 124) and on the characteristics of specific masquerade types. Questions 121,122 , and 123 (only one of which was asked of each respondent), for example, required a simple verbal statement focusing on the most significant aspect of the masquerade. Interestingly, responses to these questions center on performance rather than on costume, lending weight to a hypothesis suggested by several scholars (Cole 1971; Horton 1973; Borgatti 1976a) that aesthetic weight in a African culture falls on the performing rather than the plastic arts. There were also two series of questions on Okpella masquerade types (178-198 and 240-260), the first focusing on the visual aspect-mask and costume (itsua) - and the second on performancemusic and dance [ishimi]. The 7 types of masquerade were contrasted in all possible pairs and the respondents were asked to agree or disagree with "what people say" about the masquerades or their performance. ${ }^{6}$ This section was considered the most tedious by the Okpella respondents. However, using a paired preference technique permits respondents to be internally inconsistent in their choices, unlike simple ranking, and allows us to determine the number of factors that go into making particular choices as well as to determine the hierarchy of preference.

This technique was also used with the visual stimuli presented to the respondents in questions $138-177$ and $199-238$. The visual stimuli clustered around two concepts, the beautiful and the grotesque, represented visually in Okpella by two distinct mask types described respectively by the terms "beautiful" (osomhotse) and "grotesque" (ulishi) in the Okpella language. These images are relatively easily readable cross-culturally as belonging to these categories. Paired images representing a cluster of characteristics that are complementary in their opposition are widely found in West Africa (Blier 1974). Among the Anang Ibibio where the notions of beautiful and grotesque were specifically tested in the field (Messenger 1973), the grotesque image permitted the artist greater freedom of invention than the beautiful image in terms of his own perception. This suggests that the Okpella audience will appreciate a wider range of images as grotesque than as beautiful.

The stimuli consisted of ten images of Okpella beautiful masks commemorating individual women, ten masks from elsewhere in Africa falling into the category of beautiful within their respective cultures, ten images of Okpella grotesque masks representing the festival herald, and ten grotesques from elsewhere in Africa. Each respondent was presented with five images from each of the four categories. Each of the five images was presented in all possible paired combinations (ten pairs for 
Chart A

Ogiriga: Okpella Beautiful Masks*

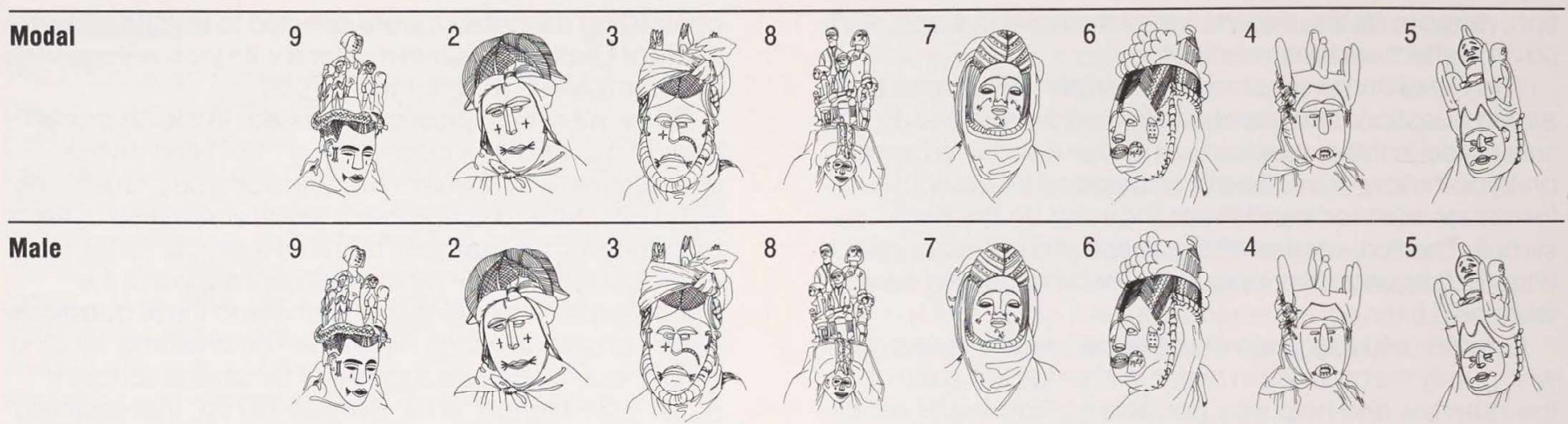

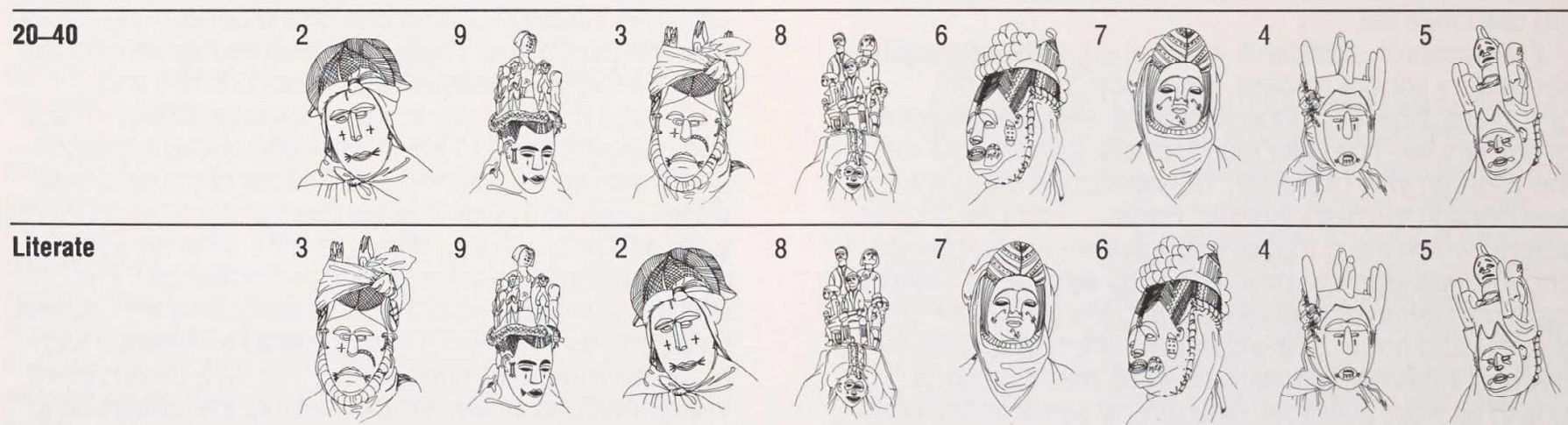

Female

Over 40

Nonliterate

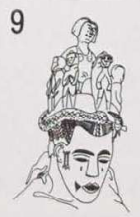

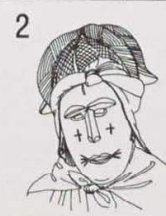

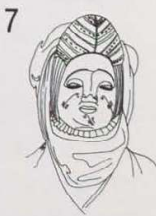

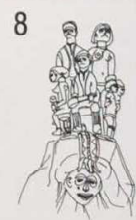

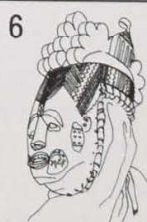

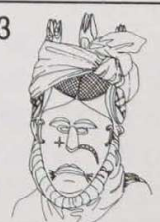

Okpella Beautiful Masks

1 Olimi Osighe (Afokpella)

Commemorative mask based on Knockout (Efofe), the Elders'

masquerade; for a woman. Artist: unknown

Borgatti 1979a: plate 14

2 Olimi Oriyekia (Iddo)

Commemorative mask, typical, for

a woman

Carver: Stephen Isah of Ogiriga, C. 1968

Borgatti 1979a: plate 8

3 Olimi Bebe (Ogute)

Entertainment version of com- memorative mask

Carver: Lawrence Ajanaku, c. 1972

Borgatti 1976b: plate 13

4 Olimi Omonase (Afokpella)

Commemorative mask for a

woman, typical but face left black

Carver: Lawrence Ajanaku of Ogiriga, c. 1969

Borgatti 1979a: plate 3

5 Olimi Imoetonoga (Afokpella)

Commemorative mask, female

type, for a man

Carver: Lawrence Ajanaku of
Ogiriga, c. 1952

Unpublished

6 Olimi Mamuna (Afokpella)

Commemorative mask for

woman, typical

Carver: Odika of Weppa Wano, c. 1928

Borgatti 1979a: plate 5

7 Olimi Obo (Ogute)

Prestige version of commemora-

tive mask; Ikot Ekpene face mask

Unpublished

8 Olimi Elewo (Iddo)

Commemorative mask, typical

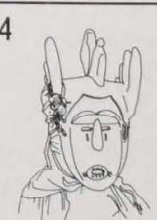

5

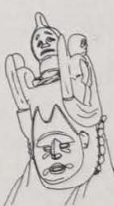


Ogiriga: African Beautiful Masks

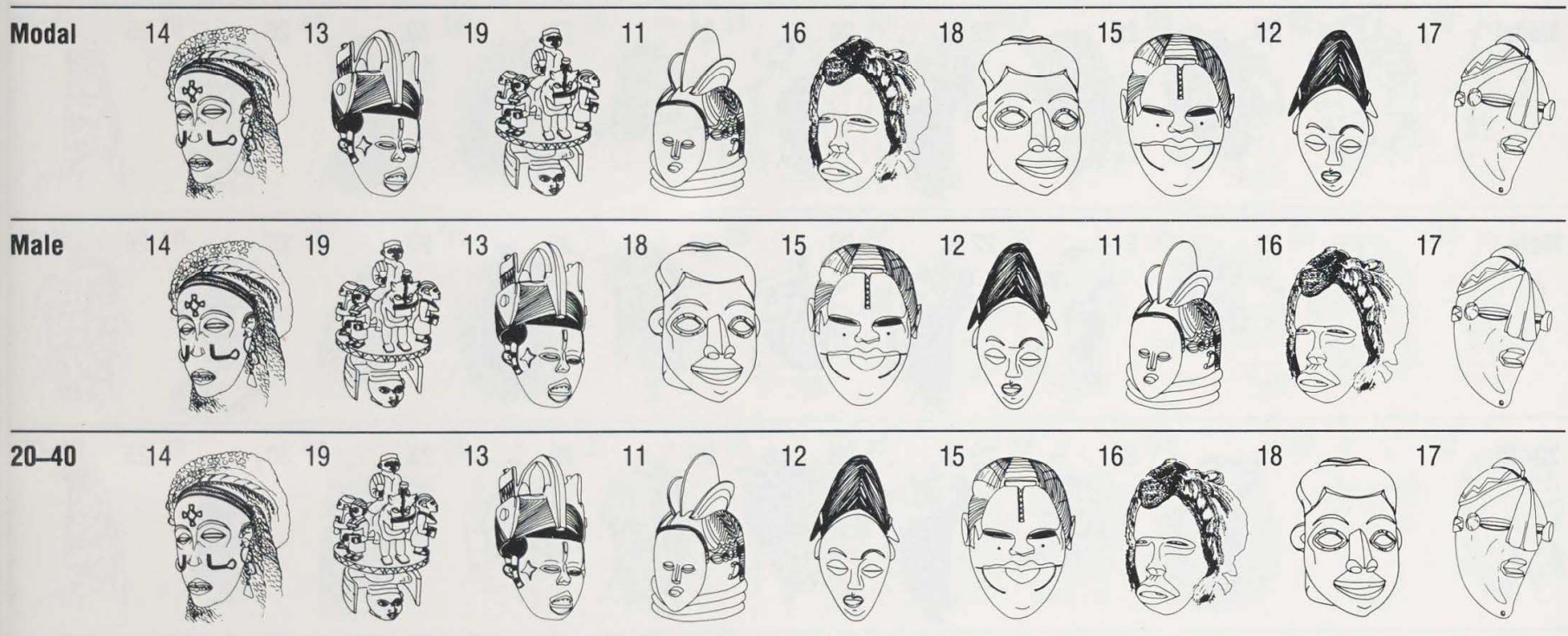

Literate
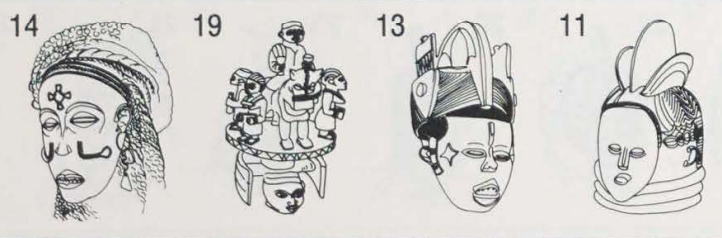

12
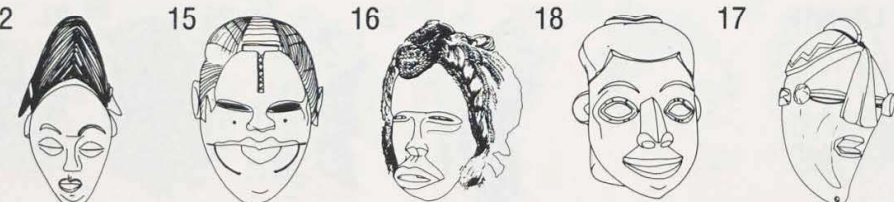
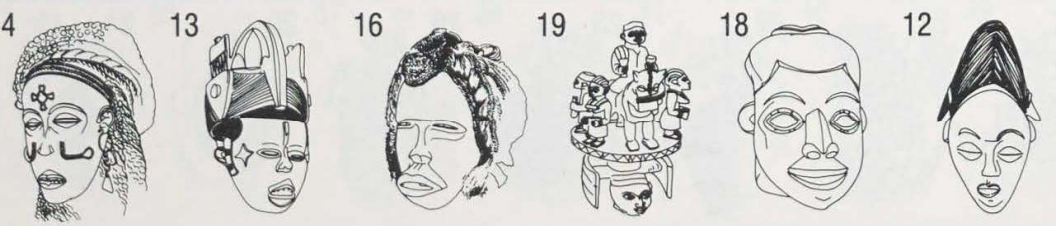

15

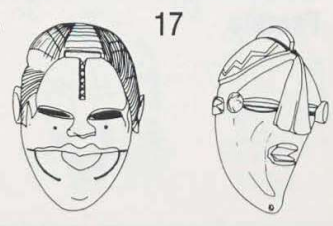

Over 40
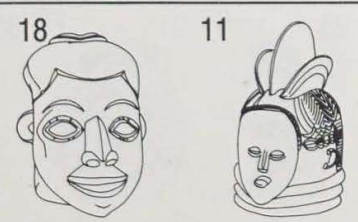

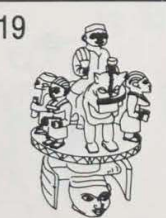

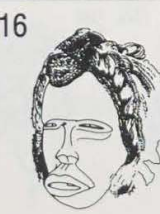
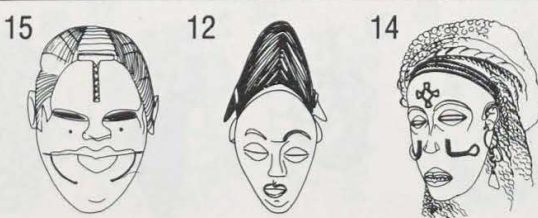

17
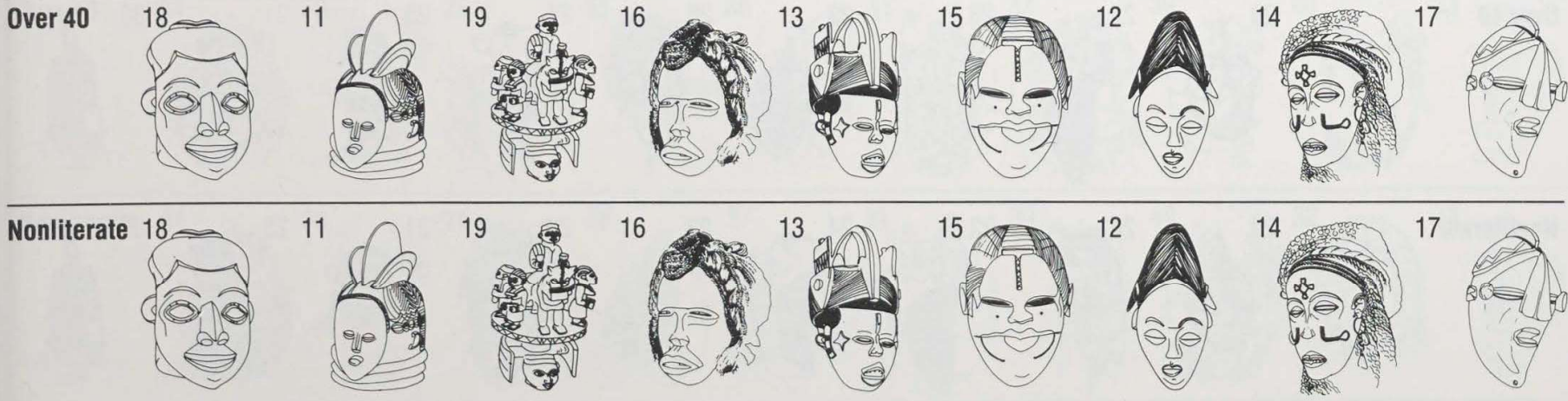

African Beautiful Masks

Collection: William and Robert Arnett

Mende? Sierra Leone

Atypical, ovoid, flattened facial plane

Source: unlocated

12 Face mask, whitened, female

Punu, Gabon

Leiris and Delange 1968: plate 142

Collection: Private

13 White-faced, female mask

Idoma, Nigeria

Witmer and Arnett 1978: plate 244

14 Female mask (Mwano Pwo)

Chokwe, Angola

Leiris and Delange 1968: plate 40

Collection: Museo do Dundo, Lunda

15 White-faced, female mask

Ogoni, Nigeria

Witmer and Arnett 1978: plate 110

Collection: William and Robert Arnett

16 Female mask

Dan, Liberia
Fagg 1965: plate 11 Collection: M. Morris, J. Pinto, Paris

17 Face mask

Lwalwa, Zaire

Fagg 1965: plate 99

Collection: MRAC, Tervuren

18 Mask representing a royal female Kom, Cameroon

Northern 1973: plate 17

Collection: Georges Rodrigues

19 Gelede mask

Yoruba, Nigeria

Afrika Museum Catalogue

Collection: Afrika Museum Berg en Dal

20 White-faced mask, animal superstructure

lbo, Nigeria

Rubin 1976: plate 47

Collection: Chaim Gross 


\section{Chart B}

Ogiriga: Okpella Grotesque Masks

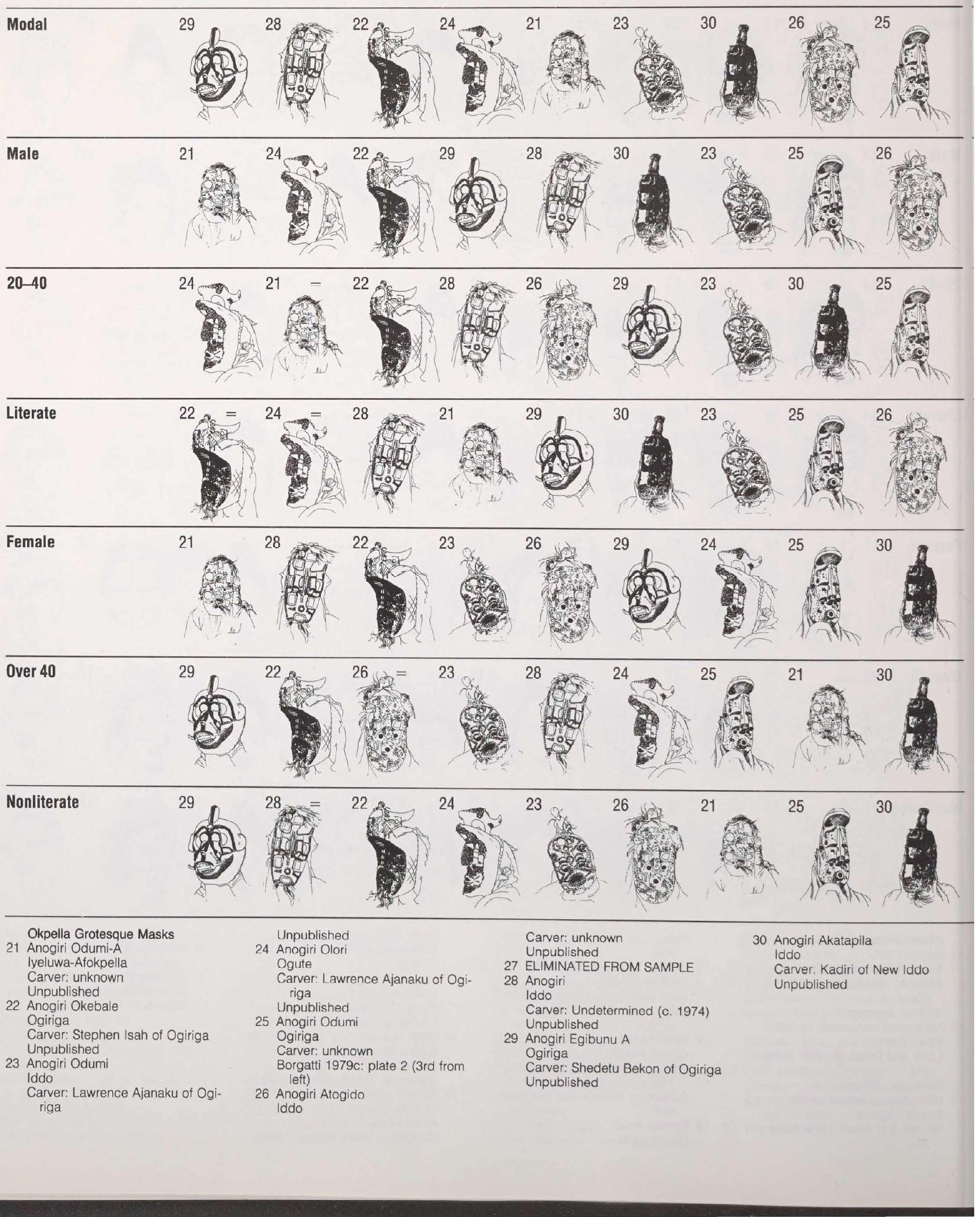




\section{Ogiriga: African Grotesque Masks}

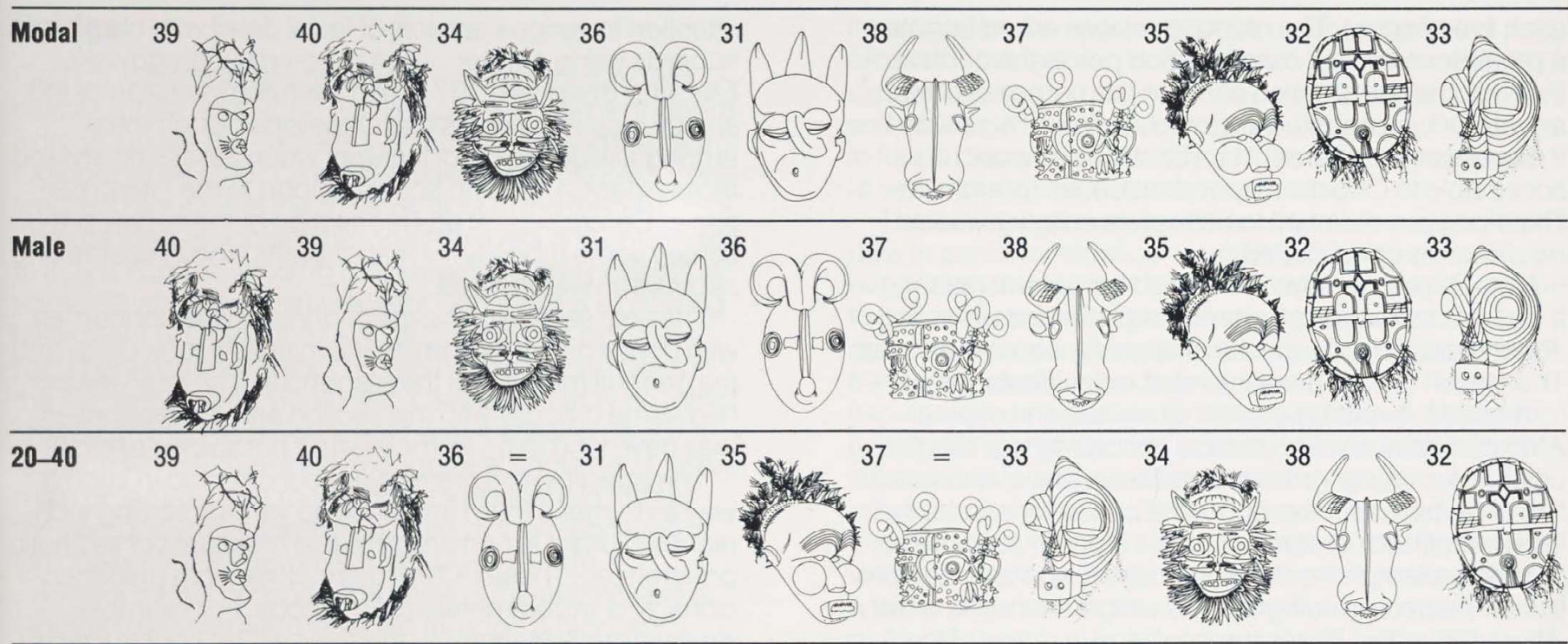

Literate 40
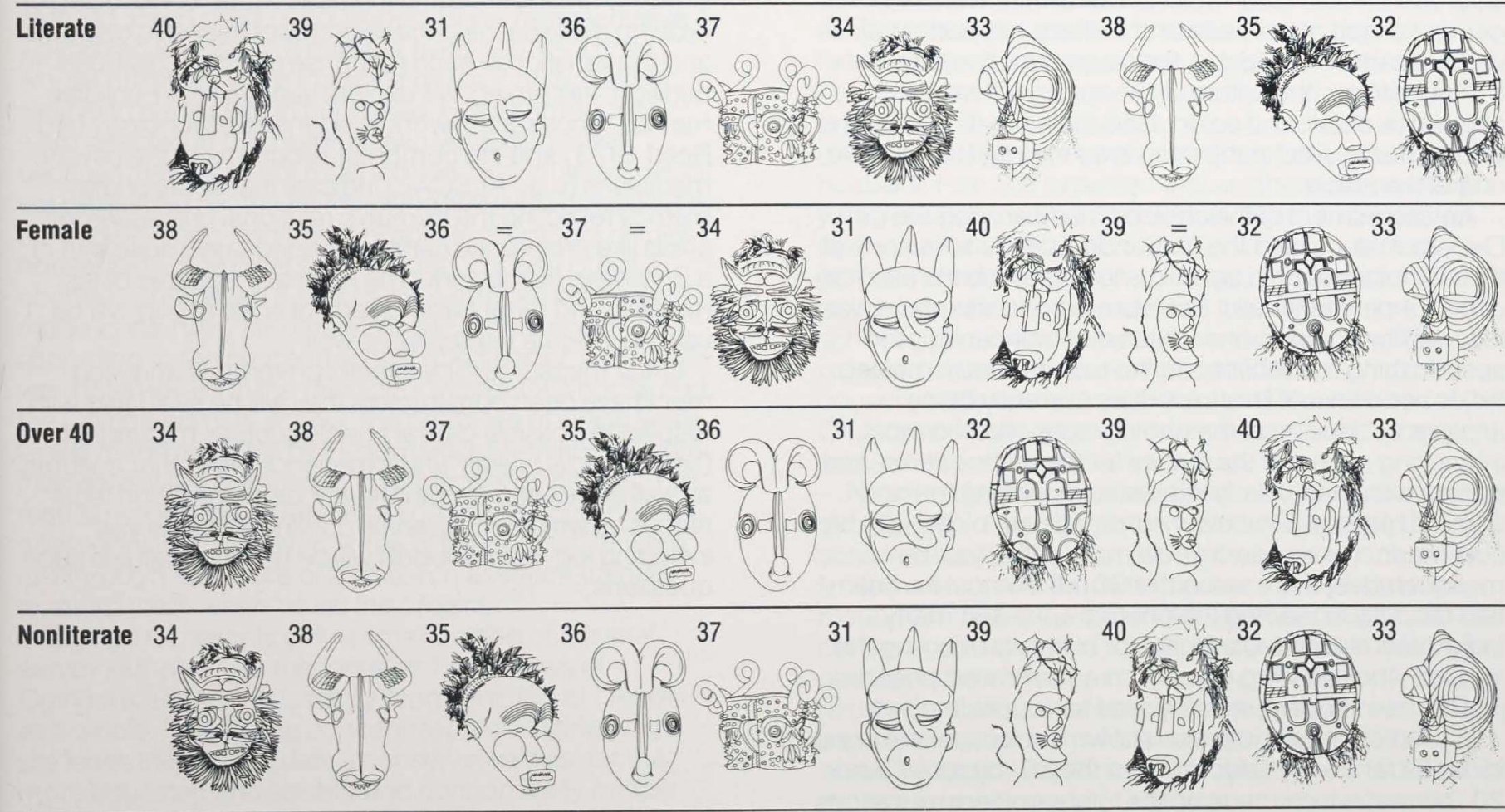

African Grotesque Masks

31 Ekpo mask

Ibibio, Nigeria

Witmer and Arnett 1978: plate

161

Collection: William and Robert Arnett

32 Face mask

Teke, Republic of the Congo

Leuzinger 1972: facing p. 276

Private collection, Paris

33 Face mask

Songye, Zaire

Leiris and Delange 1968: plate 392

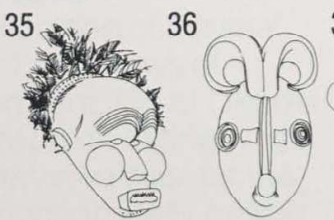

Collection: M.R.A.C., Tervuren

34 Face mask

Gere, Ivory Coast

Arnett 1975: plate 92

Collection: William and Robert Arnett

35 Face mask

Mambunda, Zambia

Fagg 1965: plate 97

Livingstone Museum, Zambia

36 Face mask

Ogoni, Nigeria

Fagg 1965: plate 54

Collection: Nigerian Museum, Lagos
31

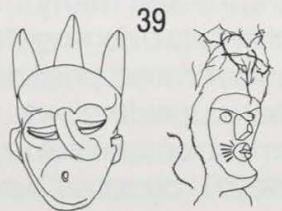

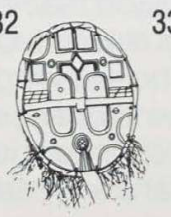

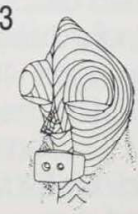


each five images). The respondent was asked to state a preference for one mask in each pair in the context of the hypothetical situation of his or her commissioning a mask of the beautiful or grotesque type. This placed the preference statement in a context that would be acceptable to Okpella respondents, even though Okpellans are reluctant to criticize openly or evaluate masks once consecrated.

Non-Okpella images were used for several reasons. It was hoped that respondents might feel less inhibited about evaluating the masks of other African peoples, as Thompson (1974) demonstrated with videotaped performances. It was expected that evaluations of other African masks would be made according to a set of criteria stemming from an Okpella aesthetic, and would therefore be instructive about the characteristics of the ideal beautiful or grotesque mask. Non-Okpella masks included examples quite close to the Okpella prototypes in their respective categories as well as examples which differed from this ideal representation in terms of the general shape of the head and coiffure, proportion of various parts to the whole, the placement and articulation of features, the nature of the surface finish and decorative detail, and so on. Line drawings based on the photographs used in the interviews may be found at the end of the article.

An assessment of the choices made among the nonOkpella material and the respondents' rationalizations of these choices should permit us to determine the elasticity of the Okpella aesthetic. Each preference statement was followed by an open-ended question concerning the specific thing that influenced the respondent in making his or her choice. (This material is currently being analyzed.) Looking at the photographs was the most interesting aspect of the survey for the respondents, and people were particularly interested in viewing the nonOkpella material. One elder summed it up nicely with his comment: "It's wonderful how many Olimi [spirits/ masquerades] there are in this world!" Almost no one had difficulty in reading the photographs and many individuals evidenced a facility for mentally orienting the images when viewing them from an overhead position, just as the interviewers easily read texts upside-down.

Each respondent was also shown a selection of images in triads randomly selected from the 20 "beauties" and 20 "beasts" which made up the total sample. In questions 261 -300, respondents were asked to state which two out of a given set of three were most alike and what characteristics he or she focused on in making a decision. This technique was intended to elicit the information that pinpoints the features or characteristics considered by individuals when making a judgment and thus to construct similarity and dissimilarity matrices that illustrate the bases of Okpella aesthetic judgment. This avenue of questioning was suggested by a study indicating that black and white subjects differed in the way they described faces. This was interpreted as reflecting differences in attention to various aspects of facial detail with black subjects using a wider range of criteria (Deregowski, Ellis, and Shepherd 1975). An overall impression of the survey results indicates that Okpellans discriminate among a wide variety of features when assessing stylized faces (masks), lending some support to the interpretation of Deregowski et al. This section of the survey presented some difficulty for respondents whose abstracting capabilities were limited. ${ }^{7}$

The final section of the questionnaire was concerned with conditions under which the interview took place and the general reliability of the responses. The interviewers had some difficulty with this section and the responses they gave tend to be formulaic and not always reliable.

The questionnaire items were constructed in such a way as to make them amenable to various scaling techniques in order to construct reliable measures of aesthetic preferences. These techniques include both unidimensional and multidimensional methods. For example, similarity and dissimilarity matrices will be constructed in order to evaluate the dimensionality of aesthetic response and the variation in such response among individuals. In addition, this project will explore various non-Euclidian metrics, since recent work in cognitive psychology (e.g., Reed 1973) and the computer programs of the psychometricians (e.g., ALSCAL) indicate that appropriate metrics reflecting the human's relational processes in areas like preference cannot be adequately dealt with in a Euclidean framework. The normal measures of test reliability and other basic criteria of scale quality will be used to validate the scales as well.

Once measures for aesthetic preference and judgment have been constructed, they will be evaluated with respect to possible causal agents such as maturation (age), special talents, and experience with other cultures, as well as sex and status differences. Regression techniques as well as multivariate contingency analysis including log-linear models will be used to evaluate such questions 


\section{Ogiriga}

Ogiriga is the northeasternmost village of the Okpella cluster. Igbira and North Ibie people, the latter a northern Edo group like the Okpella, live to the north and the east of Ogiriga, while other Okpella-speaking people live to the west and south. It is the most remote of the eastern Okpella villages, located beyond Afokpella and connected to it by a narrow, winding bush road. Ogiriga consists of some 69 afe in its main site, although there is a growing settlement of Ogirigans (Af'Ogiriga) located along the road between the major Okpella marketplaces close to the highway linking Benin with Okene. Afe may be rather loosely defined as a household with a specific physical location whose members recognize a single head, either male or female. The members of a household, that is, the persons who have the right to live there because of kin connections, may in fact reside elsewhere.

Five of the six compounds chosen for interviewing at Ogiriga main site were selected through a random method. Each head of household or his representative was asked to choose a number from 1 to 12 . Those whose numbers were matched by a roll of dice were eligible to participate in the survey. Eight compounds were selected in this manner; two were eliminated because they could not meet the sample requirements. Of the remaining six, the heads of the first five were asked to participate along with the appropriate members of their households. The chief's compound, chosen out of courtesy, completed a total of six. Arrangements were made to interview six persons in each household, according to the procedure described earlier. Individuals were interviewed in the principal investigator's house and the Ogiriga primary school, the premises of which were kindly made available by Headmaster Afemikhe. Several interviews were completed in respondents' homes. The results reported here are based on only 33 completed questionnaires, however. Three of the original 36 were lost through the failure of a research assistant-trainee to return them when he left the project.

Ogiriga represents only a small portion of the total survey sample (400 respondents). The views of Ogirigans are not necessarily representative of Okpella as a whole. Indeed, the concentration on Ogiriga main site lends the Ogiriga data a conservative bias, for the more educated and socially and economically mobile elements live in Af'Ogiriga near the main road. Of the 33 Ogirigans comprising the sample, 18 were men and 15 were women. They ranged in age from 12 to 80. Although most were farmers (21), traders (5), artisans (3), schoolchildren (3), and a traditional ruler (1) were represented. Sixteen of the individuals were nonliterate, 17 had had some schooling, but only one had earned a secondary-school certificate. With the exception of three who designated themselves as following their traditional religion, all referred to themselves as Christians. Twentyone of the 33 had some experience in working with their hands - the most important criterion for being an artist/craftsperson in Okpella; 25 claimed sufficient expertise in some performance category to perform solo, that is, to be okelo or a skilled performer. Members in four of the six households admitted to owning a total of seven masquerades.

The 33 Ogiriga questionnaires do not provide sufficient data to perform statistical procedures such as multidimensional and individual-differences scaling germaine to the analysis of the total sample. Nonetheless, certain patterns emerge, giving preliminary answers to some of the basic questions underlying the research. These expectations may be summarized as follows: First, it is expected that the Okpella people have an aesthetic, i.e. a formal system of rules for evaluating sculpture and other art phenomena. Second, given the eclecticism of Okpella masking styles, it is expected that the aesthetic will permit an appreciation or the positive evaluation of a wide range of images. Third, given our understanding of African techniques for remembering faces, it is expected that the aesthetic criteria used in relation to facemasks will address details of feature and decoration. Fourth, given the categories beautiful and grotesque, it is expected that the aesthetic of the grotesque will permit greater deviation from the norm than the aesthetic of the beautiful. Fifth, it is expected that aesthetic attitudes will vary somewhat across individuals. Sixth, it is expected that variance in aesthetic attitudes will be consistent across individuals according to age, sex, and special skills or interests. Finally, it is expected that variation in formal schooling and exposure to the outside world will be reflected in variation in aesthetic attitudes. In this article, concern rests primarily with the strength and form of the Okpella aesthetic and with those factors such as age and sex that affect aesthetic choices.

Not only does Ogiriga represent a small portion of the total sample of persons interviewed in Okpella (400 persons in nine villages), but this article focuses only on a limited selection of the 300 questions asked of each respondent. We are concerned here specifically with the preferences expressed by respondents confronted with photographs of masks in pairwise comparisons. Each respondent was presented with five images from a total sample of ten in each of four categories: (1) Okpella beautiful masks; (2) African beautiful masks; (3) Okpella grotesque masks; and (4) African grotesque masks.

The first category, Okpella beautiful masks, consisted of examples of the type of mask most often used to commemorate a deceased woman of importance-the masks referred to as Dead Mothers elsewhere (Borgatti 1979a). The generic type is a wooden, three-quarter helmet mask representing a woman with an elaborate coiffure and/or figural superstructure. Okpellans describe this mask as beautiful (osomhotse) - a term connoting happiness and contentment (lack of suffering); com- 
pleteness or fulfillment in terms of function (goodness); a perfection of physical form as well as an appropriateness of form (well made); and, importantly, embellishment or imaginatively rendered decoration (making the item better than good) (Borgatti 1979b:19).

The second category, African beautiful masks, was made up of masks generally considered feminine in type and evaluated positively within their respective cultural contexts. The masks in the sample do not necessarily represent the finest examples of their given types, but were chosen because of specific formal characteristics that in some way conformed or contrasted with those characteristics evidenced in the normative Okpella examples.

The third category, Okpella grotesque masks, consisted of examples of the mask worn by the Olimi Festival Herald (Anogiri) - a mask carved of wood and featuring an overhanging brow, a flat facial plane, and a pursed, projecting mouth. The blackened surface is studded with red abrus seeds and embellished with mirrors and cowry shells. Okpellans describe these masks as grotesque or frightful, using the word ulishi - an antonym for osomhotse that embraces in its meanings radical distortion of form or a configuration confusing to the eye (Borgatti 1979b:19).

The fourth category, African grotesque masks, included masks considered grotesque in their respective cultures, like the Ibibio "bad ghost" or mfon ekpo, or those which differed so radically from the Okpella concept of the beautiful as evinced by the Dead Mother mask that they could be considered grotesque in Okpella terms - like the disk-shaped Teke masks or the cubistic kifwebe masks of the Songye, to mention two examples from either end of a spectrum of difference. A list of masks used in the sample and the sources of published illustra tions, where available, are at the end of the article.

Each respondent was shown five masks in each of the four categories, and was shown these masks in all possible paired combinations -10 pairs for each 5 images and a total of 40 pairs in all. He or she was then asked to state a preference for one mask within each pair in the context of the questions: "If you were making a commemorative mask (Olimi) to remember your mother, which of these two would you want your own to resemble?" and "If you were making a Festival Herald (Anogiri) mask of your own, which of these two would you want your own to resemble?" This placed the question within an Okpella frame of reference, and placed the non-Okpella masks in a context in which they would be measured against an ideal image or set of criteria applied to masks representing specific characters or falling into specific performance categories.
Based on the responses to these questions, a modal profile of Ogiriga's preferences in each category was constructed - with an effort made to maintain the transitivity of the respondents' choices. Choices were also cross-tabulated with information on the respondents' age, sex, education, and special skills. Profiles in each of the four categories of imagery were then constructed, based on a ratio of the number of times a given mask was chosen over the number of times it was displayed to men, women, persons of different ages (0-19, 20-40, and over 40), nonliterate and literate persons, and persons designating themselves as craftsmen (atsona) or performers (okelo). In Okpella, the word atsona embraces all those persons who do some kind of handwork with a modicum of skill, including broommakers and hairplaiters, woodcarvers, weavers, and others. The word okelo refers to a person sufficiently skilled in some area of performance-song, dance, drumming, storytelling, and so on - that he or she may appear solo on appropriate occasions. The preference profiles keyed to numbered photographs appear at the end of the article.

The profiles reveal in a most striking way how very well-formed is the Ogiriga aesthetic, for even within this small sample of 33 individuals, there is a high degree of consistency among the three most preferred and the three least preferred masks in the ratings of each group (i.e., age, sex, etc.) vis-à-vis the rating of the masks in the modal profile for each category of image (i.e., Okpella beautiful, African beautiful, Okpella grotesque, and African grotesque). As expected, there is somewhat less consistency overall in the categories of grotesque imagery, lending support to the hypothesis that the aesthetic of the grotesque is more flexible than the aesthetic of the beautiful.

It is clear that for the people of Ogiriga, the evaluation of formal characteristics outweighed other criteria-most importantly, pride of ownership, the sanctity of age, and the weight of power-in the preferences expressed. Among the examples of Okpella beautiful masks, only one (\#10) actually belongs to the community of Ogiriga. This mask ranked in the upper middle of Ogiriga's preferences, but not most highly. Three of the nine Okpella grotesques belonged to Ogiriga, and although two of these were highly regarded (\#29 and \#22), the oldest and ostensibly most sacred mask from Ogiriga (\#25) was ranked last, while the oldest and most powerful mask in all Okpella (\#21) was ranked in the fifth position.

In assessing the non-Okpella masks, Ogirigans ranked most highly examples closest to their own prototypical models. The images most preferred among the nonOkpella beautiful masks were an Idoma three-quarter helmet mask (\#13) representing a woman with an elaborately carved and incised coiffure, and a whitened face with features and scarification marks picked out in black; and a Chokwe "beautiful maiden" mask (\#14) with features clearly defined and scarification and brow- 
line elegantly rendered in relief. The Chokwe mask's elaborate fiber coiffure provides an interesting textural variant in terms of surface design. The images most preferred among the non-Okpella grotesque masks were Igbira "messengers" (ekuecici) (\#39 and \#40)-the historic prototypes for the Okpella grotesque mask itself, i.e., the mask worn by the Festival Herald (Anogiri)

A comparison of distinctive group profiles with the modal one for each category of images revealed a correlation between the preferences of the female, over 40 , and nonliterate groups. Although these three groups are not coterminous, it should be noted that females as a group and those over the age of 40 as a group correlate highly with those who are nonliterate. There was an equally marked correlation between the preferences of the male, 20-40, and literate groups. Again, these groups are not coterminous, but the first two groups correlate highly with the group that is literate. It is important to note that the preferences of these two clusters correlated within their respective selves and contrasted with each other as well as with the modal profile across all four categories of imagery. This is illustrated in profile charts A and B.

Within the two clusters respectively, there was less consistency in the preferences for grotesque images than for beautiful ones. Again, this is consistent with the notion that the grotesque gives greater scope for expression than the beautiful in the African context. Special skills did not significantly affect choices made by respondents in the Ogiriga sample-although the choices of those who were skilled performers - okeloreflect a slightly higher percentage of women in this category than men and the choices of those persons calling themselves craftspersons - atsona - reflect the slightly higher percentage of men in this category.

Although the cluster represented by the male, 20-40, and literate groups might be expected to be the most experimental and open to innovation, it is in fact the cluster of female, over- 40 , and nonliterate groups that includes deviant masks among its most preferred ones, or excludes a more typical example in contradistinction to the mode established by the group as a whole. For example, among the Okpella beautiful masks we find in use an Ikot Ekpene face mask of the most pedestrian kind. It differs sharply from the normative mask used to represent a Dead Mother. The Ikot Ekpene mask (\#7), a framed face mask rather than a three-quarter helmet with a three-dimensional carved coiffure or superstructure, displays features that are more softly and naturalistically modelled than those of the typical Okpella mask. Its brows are thin and arched, in contrast to the heavy, rather beetling brows of most Okpella masks. Half-closed lids round over eyes contrasting with the more schematically rendered and heavily outlined eyes of Okpella masks.
Designs painted on the face are elegant and curvilinear as opposed to the generally more angular and incised patterns typically found on the faces of Okpella masks. The mask from lkot Ekpene, supremely haughty in its expression, is preferred markedly by the female, over-40, and nonliterate groups. The difference in choices evidenced by women and persons over 40 is somewhat startling in the category African beautiful masks. Women clearly preferred a Mende (?) Sande society mask with a striking triple-crested coiffure to those modally preferred. Persons over 40 and nonliterate individuals expressed a marked preference for a Kom (Cameroon) mask with its extroverted forms and shining surfaces. Both masks depart radically from the aesthetic of the beautiful demonstrated by the normative Okpella examples. In contrast, the male, 20-40, literate groups express a preference for a Chokwe "beautiful maiden" (mwana pwo] mask (\#14) much closer to Okpella prototypes than the masks mentioned above in the refined stylization of its features and emphasis on decorative detail.

In the category of Okpella grotesques, both men and women ranked most highly the oldest mask in Okpella (\#21) in contradistinction to the modal profile where this mask falls into the middle range of choices. Women's choices differed from men's in this category, however, since they ranked more highly a mask with a clearly delineated and symmetrical pattern of abrus seeds and mirrors (\#28) than did men. The weight of the men's choice fell on a mask with a superstructure in the form of a chameleon (\#24), a symbol of seniority in Okpella. Much more distinct differences in preference were evidenced in choices made among the non-Okpella grotesque masks. In this category, the female, over- 40 , and nonliterate groups consistently ranked a Mambunda mask (\#35) or a Grassfield's buffalo (\#38) more highly than the Igbira "messenger" (ekuecici) mask (\#39), the mask ranked most highly in the modal profile. The Mambunda mask (\#35) is not dissimilar from Okpella's Festival Herald with its bulging brow, flat facial plane, and projecting features, although the Mambunda mode is rounded and blown rather than angular and spare. The buffalo is relatively more naturalistic than Okpella's typical Festival Herald (Anogiri) mask, although it fits within an overall conception of what would be an appropriate Herald image as an animal with horns. More significant, perhaps, is this cluster's consistent low ranking of the two lgbira "messenger" masks (\#39 and $\# 40$ ), the archetype for the Okpella Festival Herald (Anogiri), ranked first and second in the modal profile and by the male, 20-40, literate cluster of individuals.

That the cluster we expect to be most conservativefemales, those over 40 , and nonliterates-proves to be more open to innovation or modification of design demands some explanation. In Okpella, women as a group and men over the age of 40 fall into the category "spectator" rather than "performer" in masking displays featuring the Dead Mother (Olimi) or Festival Herald 
(Anogiri). These are the people who might be expected to be the most secure in their understanding of Okpella's aesthetic, for they especially view, appreciate, and comment upon the masks as members of the audience. Moreover, these are groups whose social positions are also reasonably well-defined, as opposed to that of men in the 20-40 age bracket who are in the process of establishing themselves. ${ }^{8}$ Men in the 20-40 age group, involved in other affairs (especially today), may accept existing norms rather than expend any energy thinking about them. On the other hand, men in the 20-40 age bracket perform these masks. Because wearing a mask places one in a ritually dangerous and liminal state, performers may be more concerned with "correctness" of appearance than with "interesting variation." 9 Because women as a group and men over the age of 40 are members of the audience rather than performers, they may be freer to think about aesthetic issues and thus to play the role of informal critic.

Since the Okpella people in general do not choose to articulate preferences or to discuss the merits of one mask over another in informal conversation, the Okpella aesthetic - or the Ogiriga version of that aesthetic - must be reconstructed from the choices made by respondents in the formal context of the survey. Clearly, the Ogiriga variant of the Okpella aesthetic is well-formed, for people can be shown to adhere to and depart from it in ways consistent with their own interests as represented by the categories of sex and age. These seem to be the most significant distinguishing factors for the Ogiriga sample with regard to this set of questions, and the other factors - education, craft, and performance skills - simply reflect the age and sex differences. A comparison of the most and least preferred masks in each category of imagery should outline the formal characteristics considered most appropriate for the masks functioning in a given category and meant to communicate a certain range of ideas to the audience.

A preference for elegance of shape, clarity in the definition of masses, clearly rendered and delicate surface ornamentation, symmetry, and an interest in decorative detail is evidenced in the comparison of most- and least-liked masks in both Okpella and non-Okpella beautiful categories. The least-liked Okpella mask actually commemorates a man, rather than a woman, and seems to be a coarser and more powerful sculpture than the more typical Dead Mother mask. It is almost completely lacking in decorative detail - the texturing of the surface of the head and coiffure, the carefully raised and delineated features (lips and eyebrows), and the more delicately incised and painted scarification patterns.
The most preferred non-Okpella beautiful masks, a Chokwe mask (\#14) and an Idoma mask (\#13), resemble closely the preferred Okpella types, although they are much finer carvings from the point of view of the Western connoisseur. The least preferred non-Okpella mask, a Lwalwa mask (\#17), differs sharply from more admired masks and Okpella prototypes in the cubistic angularity of the overall conception of form, in proportion, in the placement of features, and in the absence of decorative detail. The Lwalwa mask was considered completely unsuitable to the Ogiriga audience as beautiful, for it was rejected by all respondents - the only mask in the entire sample that was never chosen by anyone under any circumstances.

Among the grotesque images, a preference for clearly articulated sculptural forms and symmetrical but imaginative decoration emerges from a comparison of the most and least admired masks. The least-liked grotesque (\#25) perhaps represents an earlier aesthetic with its soaring forehead, while the others which were not well liked (\#26 and \#30) were sculpturally more amorphous - the char acteristic overhanging brow, flat facial plane, and projecting features lacking definition - while the decorative scheme of abrus seeds, cowry shells, and mirrors on \#26 is random and haphazard. The most-liked mask departs from the generic Herald (Anogiri) form described above, adding the fillip of novelty, in that it represents a bush-pig with eyes set close together over a long, projecting snout. Forms are emphasized and a second face is defined by the symmetrically placed mirrors and the linear patterns of abrus seeds playing over the surface of the mask. Of the non-Okpella grotesques, the Igbira masks (\#39 and \#40) are closer to the generic configuration of the Okpella Herald than are the others. The Igbira masks display a characteristic overhanging brow, flattened but slightly concave facial plane, projecting features - the pursed, projecting mouth beneath the nose like a dot completing an exclamation point. The masks carry a tangle of fibrous materials on the head that make an interesting textural contrast with the smooth and polished planes of face and that connote power to the Okpella audience. An incised pattern at the corner of the mouth is the only surface ornamentation. The least admired non-Okpella grotesques were an Ibibio helmet mask, horned and bumpy (\#32), and a Songye mask of the type generally referred to as "Kifwebe" (\#33). In assessing what is appropriate in a grotesque mask, Ogirigans appear to appreciate not only the ambiguity created by surface patterns but a more complex interplay of surface pattern with three-dimensional form. In looking at a less familiar range of images, Ogirigans seem to prefer key characteristics which assist in developing the Herald's complex character, appreciating the aggressive animal imagery found in the curving horns of \#36 and \#38 and the bristling additive elements of \#34, or the humor inherent in the twisted nose of \#31. 


\section{Summary}

Briefly, the most important criterion, or valued quality, in a beautiful mask is clarity; in a grotesque mask, it is ambiguity, deriving not from formlessness but from a visual punning between surface ornamentation and sculptural form. Decorative detail is valued for both beautiful and grotesque types.

One more step remains to be taken in this analysis and this is to bring out the critical vocabulary and the critical focus of Ogirigans by carefully assessing the comments that respondents made following each statement of preference. In this way the aesthetic inferred from the objects will be qualified and elaborated. These comments must be tabulated and cross-referenced with the categories of age, sex, education, and special skills to determine whether or not any significant patterns emerge and to see if the notion is substantiated that women as a group and men over the age of 40 are Okpella's most informed and articulate critics.

As indicated in the introduction, this article constitutes a preliminary report on recent research and focuses on a limited sample of the total number of individuals surveyed for their responses to questions designed to elicit aesthetic commentary, as well as on a limited selection of the questions themselves. The entire data set provides much greater scope for analysis, as should be evident from a careful consideration of the information set forth in the section on methodology. Not only can the issues considered here be assessed with the greater finesse permitted by a larger sample, but comparative village studies may be carried out on a variety of questions significant in the light of Okpella's art and its complex history.

\section{Notes}

1 A summary version of this analysis may be found in Borgatti, $1976 \mathrm{~b}$ and $1979 \mathrm{c}$.

2 Research in Okpella between 1971 and 1974 was partially funded through an NDEA Title VI grant for graduate work, the Altman Memorial Award (Museum of Cultural History, UCLA), and the UCLA Patent Fund. Funding for the 1979 research was provided through a grant from the SSRC-ACLS Joint Committee on Africa.

3 This article is based on a paper written under the auspices of a Mellon Fellowship in the Humanities at the University of Pennsylvania (19791980). Continued analysis of the Okpella aesthetics data is being funded through a grant from the National Science Foundation.

4 The survey of aesthetic attitudes in Okpella was designed with the assistance of a specialist with experience in cross-cultural survey research, Donald G. Morrison, currently director of the Center for Social Science Computation and Research at the University of Washington, Seattle. Morrison is supervising the statistical analysis of the survey data.

5 The questionnaire was first translated by two Okpella-speaking university students in Ibadan, then back-translated by the research assistant with whom the principal investigator had worked closely between 1972 and 1974 in Okpella. Questions and translations were adjusted with the latter's assistance.

6 An analysis of this material for Ogiriga was presented in 1980 at the African Studies Association Meetings in Philadelphia. This analysis is being published in a special volume on African art by Bashiru: A Journal of the Department of African Languages and Literature. Madison, WI: University of Wisconsin.

7 Respondents had less difficulty answering "which is most different? Because the questionnaire was so long, this question was not incorporated into the format. For precision in the analysis, however. both questions should be asked. (Personal communication, Charles Jones, 1980.)

8 This is the group most active traditionally in the junior night society lyabana whose songs during the annual ancestral festival focus on the conflict between personal ambition and community cohesion; cf. Borgatti $1976 a$.

9 I am indebted to Dr. Margaret Hagen of the Psychology Department at Boston University for this suggested interpretation.

\section{References}

- Arnett, W. 1975 The West Guinea Coast. Decatur, Ga.: Agnes Scott College.

- Blier, S.

1974 Beauty and the Beast. New York: Interbook.

- Borgatti, J.

1976a The Festival as Art Event, Form and Iconography: Olimi Festival in Okpella Clan, Etsako Division, Midwest State Nigeria. Unpublished Ph.D. dissertation, Department of Art History, University of California at Los Angeles.

1976b Okpella Masking Traditions. African Arts 9(4):24-33

1979a Dead Mothers of Okpella. African Arts 12(4):48-57.

$1979 \mathrm{~b}$ From the Hands of Lawrence Ajanaku. Los Angeles: Museum of Cultural History Pamphlet Series Vol. 1, 6

1979c Art and History in West Africa: Two Case Studies. In The Visual Arts (World Anthropology Series). J. Cordwell, ed Pp. 567-592. The Hague: Mouton.

- Cole, $\mathrm{H}$.

1971 African Arts of Transformation. Santa Barbara, Calif. 
- Deregowski, J. B., H. D. Ellis, and J. W. Shepherd

1975 Descriptions of White and Black Faces by White and Black Subjects. International Journal of Psychology 10(2): 119-123.

- Fagg, W.

1965 Tribes and Forms in African Art. New York: Tudor

- Horton, R

1973 The Kalabari Ekine Society: A Borderland between Religion and Art. In Peoples and Cultures of Africa. E. Skinner, ed. Pp. 600-627. Garden City, N.Y.: Natural History.

- Leiris, M., and J. Delange

1968 African Art. London: Thames and Hudson

- Leuzinger, E.

1972 The Art of Black Africa. London: Studio Vista

- Messenger, $J$

1973 The Role of the Carver in Anang Society. In The Traditional Artist in African Societies. W. D'Azevedo, ed. Pp. 101-127. Bloomington, Ind.: Indiana University Press.

- Northern, T

1973 Royal Art of Cameroon. Hanover, N.H.: Hopkins Center Art Galleries, Dartmouth College.

- Picton, J.

1974 Masks and the Igbirra. African Arts 7(2):38-41

- Reed, S. K.

1973 Psychological Processes in Pattern Recognition. New York:

- Rubin, A

1976 The Sculptor's Eye: The African Art Collection of Mr. and Mrs. Chaim Gross. Washington, D.C.: Museum of African Art.

- Thomson, R.F

1973 Yoruba Artistic Criticism. In The Traditional Artist in African Societies. W. D'Azevedo, ed. Pp. 19-61. Bloomington, Ind. Indiana University Press.

1974 African Art in Motion. Berkeley, Calif.: University of California Press.

- Witmer, M., and W. Arnett

1978 Three Rivers of Nigeria. Atlanta, Ga.: High Museum 